Vol. 2, Issue 1 (June 2020)

Journal of Education, Innovation, and Communication

DOI: https://doi.org/10.34097/jeicom_2_1_june2020_3

Pages 45-57

\title{
Situational Factors and Increased Workplace Burnout: A Study of Influences Affecting Current Younger Employees
}

\author{
Kiahni McFadden ${ }^{1}$ \\ Michael A. Altamirano ${ }^{2}$
}

\begin{abstract}
Workplace burnout has been on the rise in recent years, and stress is a significant contributor. The World Health Organization (WHO) considers burnout as an "occupational syndrome," which is often a result of chronic stress. There has been an emergence in topic related studies, a need for clarity, diagnosis, and treatment regarding workplace burnout. The need for continual research is essential for further understanding of this phenomenon. Burnout has two contribution factors; situational factors and individual factors that contribute to stress. Situational factors include job demands and resources. Individual factors include financial situations and individual personality. These factors can affect the way persons respond to overloaded work responsibilities. This condition often results in a reduction in professional efficacy and productivity. This research explores workplace burnout in employees under the age of 50, often referenced to as younger employees and the relationship between workplace burnout and situational factors. Exploring the effects of why workplace burnout has increased in recent years could lead to a better understanding of the condition, and the suggestion of measures to reduce burnout. The research of burnout would be beneficial toward the continued understanding of global workplace behavior as it relates to the topic of stress management.
\end{abstract}

Keywords: workplace burnout; burnout; occupational syndrome; stress, stress management.

\footnotetext{
${ }^{1}$ MBA Candidate, King Graduate School, Monroe College, Bronx, NY, kmcfadden3463@monroecollege.edu

${ }^{2}$ Ph.D., MBA Professor, King Graduate School, Monroe College, Bronx, NY, maltamirano@ monroecollege.edu
} 


\section{Introduction}

This article discusses the importance of further research regarding factors related to workplace burnout, situational factors, and how it affects personal mental health. Workplace burnout has become a concern worldwide in several industries and has affected all age groups that are in the workforce. The majority of current research has been focused on the top ten professions that have the most workplace burn as physicians, nurses, social workers, teachers, school principals, attorneys, police officers, public accountants, food service workers, and retail workers; due to these professions being highly-stressful, and highly demanding.

The World Health Organization (WHO) is embarking on the development of evidence-based guidelines on mental well-being and its connection to workplace burnout. In May 2019, the WHO estimated that 264-million people suffer from depression, one of the leading causes of disability. According to the WHO, repeat episodes of depression or extended periods of depression can be diagnosed as clinical depression. Clinical depression has been linked to workplace burnout, which can affect several aspects of a person's daily life and workplace responsibilities. Depression and disability have become costly in the workplace, and cost the global economy \$1-trillion US dollars annually in lost productivity.

Situational factors are job demands and resources that can affect the way that an individual responds to work responsibilities that can become work overload and lead to unhealthy mental wellbeing. Workplace burnout is defined as a syndrome conceptualized as a result of chronic workplace stress that has not been successfully managed. Work overload is significantly connected or associated with burnout and emotional exhaustion. A negative work environment can lead to physical and mental health problems, such as absenteeism, lost productivity, and high employee turnover. 


\section{Literature Review}

The articles and research shared in this narrative review serve to enrich the research findings of this study by presenting other published research regarding the connections of stressors, depression, and workplace burnout. Past evidence has underestimated burnout and its relation to depression. Prior studies revealed that higher levels of pressure in the workplace led to lower self-efficacy and tiredness at work. A possible source of stress may result from personal cognitive assessment as a form of response to one's own pressures that eventually lead to burnout. Low self-efficacy can lead to setbacks, attribute to success or failure, and neglect the factors of their inner ability and efforts.

The study "The Buffering Effect of Workplace Resources on the Relationship between the Areas of Worklife and Burnout" (Jiminez \& Dunkl, 2017) explores the benefits of workplace resources and their role in workplace burnout, related to the stress-strain relationship. This study used a longitudinal sample of 141 Austrian workers that participated in two online studies over two-years. The results showed that workload is connected to emotional exhaustion and work rewards and values are related to cynicism, but only if resources are available in the workplace. Further moderating effects of resources supported the outcome of personal accomplishment. Workplace resources showed an increase in personal accomplishments. The study concluded that despite the short time of two-years, there was evidence that workplace resources were essential in prevention factors for burnout. The study also showed that employees that experienced high levels of control in a low resource workplace showed fewer personal accomplishments. Additional research and investigation are needed regarding workplace burnout stressors relationship for a more extended period to understand the full impact and benefits of workplace resources.

Schonfeld and Bianchi examined the overlapping of burnout and depression (2016). The researched group of 1,386 teachers in 18 United States public schools participated in the study seven months during a school year. The depression module of the Patient Health Questionnaire concluded that the magnitude of burnout and depression overlapped, and treatment for depression would be beneficial for workers that identified as being burnt-out. 
"A fundamental factor, however, that links burnout and depression is the stress of not having control over one's environment. According to the learned helplessness theory, when an individual perceives that exerting control of his or her environment, particularly in aversive situations (and accessing important resources and pursuing major goals), is impossible, then the individual may no longer attempt to cope with such situations and become at risk for depression" (Gilbert, 2000; Peterson, Maier, \& Seligman, 1993).

Many burnout patients exhibit motivational patterns reflective of learned helplessness (Peterson et al., 1993; Van Dam, Keijsers, Eling, \& Becker, 2015)" (Schonfeld, \& Bianchi, 2016). The study revealed there was a strong correlation between burnout and symptoms of depression and that traditional depression treatments were beneficial to help employees experiencing workplace burnout.

In a study involving teachers, Yu, Wang, Zhai, Dai, and Yang, 387-middle-school teachers completed the Perceived Stress Scale questionnaire in a classroom setting. All participants were aware of the research background, and purpose, and provided written consent to participate in the study. The study revealed that stress positively correlated with burnout, and self-efficacy did correlate negatively with burnout. The findings of this study showed that prior researchers provided valuable evidence on how mental health with provided resources, was beneficial in the workplace. Multiple studies identify stress as among the direct causes of job burnout among teachers and job burnout as an extreme form of workrelated stress (Kyriacou, 1987). At present, teachers are being pressured mainly by role conflict, role ambiguity, relationship with students, relationship with colleagues, work overload, long working hours, and high work intensity, all of which cause mental and physical exhaustion, frustration, depression, and passive or indifferent perspectives toward life and work (Slick1997; Yankelevich et al. 2012). When work-related pressure is not alleviated promptly and effectively, teachers tend to lose their passion for education as well as teaching. They experience a state of overwhelming tiredness, completely lose their motivation, and begin demonstrating passive, negative, or apathetic attitudes toward their students. Therefore, a high level of pressure tends to excessively consume the passionate and physical resources of teachers, ultimately leading to an unembellished state of job burnout (Jou et al. 2013; Peng et al. 2013; Veldman et al., 2013). The study supports that self-efficacy has an effect on burnout (Yu et al., 2015). 
Organizations are capable of taking a proactive approach to burnout. A study by Del Bosque and Karl focused on exploring workplace burnout, and the measures organizations can take to help employees through training and education (2016). Findings show three cognitive functions to have a connection to burnout, executive functions, attention, and memory. The connection of high levels of work pressures and cognitive demands lead to burnout (Golanka, Mojsa-Kaja, Gawlowska, \& Popiel, 2017). Furthermore, suggesting individuals experiencing burnout also experience impaired cognitive function as well as attention and memory problems (2017).

The shared articles and research in this literature review have shown that additional research is needed to understand burnout better. Employee assistance has been linked to being a benefit to decreasing burnout and has proved to reduce connections of stressors, depression. As additional research is done in the future, it will provide clarity, diagnosis, treatment, and understanding of this global workplace "occupational syndrome."

\section{Methodology}

The research for this article is qualitative in nature incorporating interviews and the analysis of respondent data. The reason for conducting a qualitative study was to learn more about the opinions and motivations of respondents in relation to this topic. What resulted was a deeper and more holistic understanding of the nature of burnout.

Participants of the study represent individuals under 50-years of age and work full-time (40hours/weekly). The specific logic behind the participant qualifications was simply an attempt to narrow the pool of respondents, while considering respondents over the age of 50 mostly find themselves settled or on the path to becoming more settled career-wise after that age. The researchers decided not to share the interview questions (Appendix I) before meeting participants for the interviews. There was a consensus that respondents could potentially have biased opinions if they knew of the topic ahead of time. 
The participant breakdown as follows:

- Participant A - Foster Care Life Coach

- Participant B - Retail Team Lead

- Participant C - Military Personnel Division

- Participant D - Foster Care Case Planner

- Participant E - Paraprofessional

- Participant F - Retail Marketing Manager

- Participant G - Transportation Security Administration (TSA) Transportation Security Inspectors

- Participant H-Social Worker

- Participant I - Special Education Teacher

- Participant J - Department Leader - Engineer

The approach to the research within this article incorporated a thematic interpretative analysis to understand the phenomenal nature of the topic of burnout through the experiences of others. As a result, the study is exploratory with a focus on the contributing factors and effects of burnout. It is important to note that the analyzed data is from a limited sample within one geographic area and does not represent the universal views or results of a global population. The study therefore offered an intimate exploration of stressors that contribute toward feelings of anxiety and burnout among a select group of respondents.

The participants for this study represent a cross-section of individuals from different industries whom were all willing to discuss their personal experiences within the workplace regarding the topic of this study in a relaxed and transparent manner. Respondents responded to open-ended questions that led to discussion, and participants were encouraged to expand freely. The use of predetermined questions supported the process of uncovering information relevant to the burnout. Responses produced purposeful sampling through the cooperation of individuals directly affected by issues of burnout. 


\section{Burnout}

Workplace burnout is work-related stress that can cause physical or emotional exhaustion that can affect a reduction in professional accomplishments and loss of personal identity. Many of the participants for this study described how the leadership within their workplace has a significant impact on how they responded to their workload or work responsibilities and can have an effect on their personal life. Studies have shown that employees under the age of 50 suffer from emotional symptoms, work imbalance between work-life balance more often, which can lead to stress or failure to complete their work.

Participant E - Paraprofessional discussed,

"Workplace burnout is when someone is overworked and underpaid, which leads to burnout from working too many hours. I don't feel that in my current position, I fall under the work burnout category because I'm new to this position, and it is a position that allows me to do something I like and enjoy. I'm here to do whatever is need for now, so I'm not burned out yet. In the past, in another position and company, I was very stressed. My personality changed, I was irritable when I was at work, I wouldn't smile, and I had to bring work home, which brought stress onto my family."

According to the WHO (2019), there are three dimensions to burnout, feelings of depletion or exhaustion, an increase of mental distance from job responsibilities or negative or cynicism related to job responsibilities, and reduced professional efficacy. The symptoms of depersonalization can lead to severe emotional stress, trauma, and a connection to exhaustion, which can lead to a lack of personal accomplishments, decrease in feelings of competence, decrease in self-efficiency, and decrease in the sense of achievement. 
JEICOM, Vol. 2, Issue 1 (June 2020)

Situational Factors and Increased Workplace Burnout: A Study of Influences Affecting Current Younger Employees. McFadden \& Altamirano

Participant G - Transportation Security Administration (TSA) Transportation Security Inspectors stated,

"I have experience being stressed and depressed from work. Work became a chore, and I had to force myself to go to work daily. This all affected my health and motivation."

Participant $\mathrm{H}$ - Social Worker has similar sentiments,

"Our team leaders are more concerned about numbers. We are required to maintain a certain caseload without regard to quality. This stresses me out."

Misleading and lack of communication can become an issue between employees and management. This can lead to emotional exhaustion, depersonalization, and diminished personal accomplishment. Some researchers believe, "emotional exhaustion was the trait of burnout that was more consistently related to the group of institutions with more unfavorable working conditions regarding autonomy, organizational support, and control over the environment." (Nogueira, L.S., Sousa, R.M.C., Guedes, E.S., Santos, M.A.D., Turrini, RNT., Cruz, D.A.L.M.D., 2018).

Participant B - Retail Team Lead stated,

"There are several days that I feel burned out from work; it would help if management would provide accurate staffing, training, and plan ahead for certain situations; my stress level would decrease. It would also be beneficial if management would jump in and help at stressful times. Assistance from management can make a big difference in a stressful situation.”

Participant J - Engineer also contributed,

"I love what I do, but sometimes I feel I am taken for granted. As my division's team leader, I am responsible for training new staff. I do not like doing this, and every time I have to, I get anxiety. I know how to do the job, but I am not a trainer, and my bosses could care less. Having new employees go through an organized training program would take immense pressure off of me."

Different types of leaders have different effects on employees, which leads to different responses in the workplace. Transformational leadership can heighten the consciousness of employees to achieve organizational outcomes that lead to personal outcomes. Studies show that "organizational outcomes, including subjective assessment of organizational performance, absenteeism, and average sales.” (Zhu, Chew, \& Spangler, 2005). 
Leaders should use communication to encourage intellectual and mental stimulation to increase employee intelligence, knowledge, and learning within the workplace. This type of leadership helps employees to learn to be innovative in their approach to problem-solving and solutions. Organizational learning and innovation are an essential part of and promote leadership support and improve performance. Organizational learning involves cognitive and behavioral changes, which are crucial to decreasing burnout in the long-term. Studies show that an essential part of reducing workplace burnout will be leadership support. Transformational leadership is an example of leadership support, which is beneficial to both employees and management. "Transformative leaders have charisma, provide inspiration, and promote intellectual stimulation." (Bass, 1999; Bass and Avolio, 2000; Conger, 1999) A good transformational leader will motivate followers to aim for goals that are beyond their initial vision and self-efficacy and improve outcomes. Self-efficacy belief has an impact on how a person feels about their self through thoughts, emotions, and actions, which affect an individual's mental health. A leader can have a significant influence on a follower's self-efficacy through motivation and mentorship. Motivation is a primary domain for a follower's development and leadership support system.

Participant D - Foster Care Case Planner stated,

"I had a supervisor at my agency that was in graduate school, and she incorporated a work support group that meets every other Friday after workhours to allow staff to discuss challenges, share ideas, and complain about work in a safe place. We discussed our "Rose and Thorn" for the week. This made me feel heard and less stressed at the end of the week. I actually looked forward to those Fridays."

Workplaces that promote mental health awareness and support are likely to decrease these risk factors related to depression and create a healthy workplace. It is suggested that "managers, executives, human resource specialists, and design consultants can keep the physical work setting from undermining the success of workplace initiatives-that encourage high performance.” (Becker, F.D., Steele, F., 1995).

Due to the rapid changes in the workplace, it has created uncertainty and direct pressure on individuals. There has been an increase in the amount and intensity of requirements for enterprises and organizations. Work-life balance has been shown to had a tremendous effect on the psychological characteristics of individuals and how they handle rapid developments in society and how they respond. 
Participant F - Retail Marketing Manager expressed,

"Answering phone calls and emails are not a requirement for my job, but it is an expectation by upper management. Answer calls and emails during off-hours makes me feel frustrated, and it invades my personal time."

Studies have shown the correlations of psychological capital with emotional labor strategies can lead to burnout and trigger other health conditions. Some health conditions that are related to stress are mental health, heart disease, cholesterol, type 2 diabetes, cardiovascular disorders, musculoskeletal pain, fatigue, headache, gastrointestinal issues, reparatory problems, and mortality. Burnout can also lead to a lack of sleep, metabolic syndrome, and lead to exhaustion and weariness, which all show the link between work-life balance.

An individual's health can be affected in many ways, which can lower cortisol levels. Cortisol levels help to activate the immune system and other stress responses within the body. Reduced cortisol levels can lead to hyperactivity of the immune-inflammatory responses. Hyperactivity of the immune system can lead to chronic diseases such as cardiovascular disease, diabetes, and cancer. Underlying health conditions can result in a decline in overall health that can be from burnout.

Burnout can lead to a lack of sleep, metabolic syndrome, and physiological effects, which are all known to lead to cause a lack of concentration, exhaustion, and weariness. The link between overall health and burnout shows how vital work-life balance is to an individual's health.

Participant G - Transportation Security Administration (TSA) Transportation Security Inspectors suggested,

"If more workplaces offered more vacation days, and a mental health person on staff stress levels would be reduced in more workplaces."

Participant A - Foster Care Life Coach suggested,

"Offering mental health days, support from management, and teamwork would be beneficial in the workplace." 
Stress reduction programs would be beneficial for companies to create a healthy workplace balance for employees and promote work-life balance. Some examples of stress reduction programs would be stress-reducing training, wellness programs, initiatives to help with awareness and techniques, and cognitive behavior therapy. These types of programs could lead to an increase in job satisfaction.

Job satisfaction is essential to employees because it affects a person's overall happiness, job satisfaction, decreased absenteeism, and lessens workplace burnout. It is suggested that managers "provide their employees work hour flexibility, work schedule flexibility, flexibility in the workplace, promoting health, and a healthy lifestyle, promoting well-being and preventing stress and burnout in

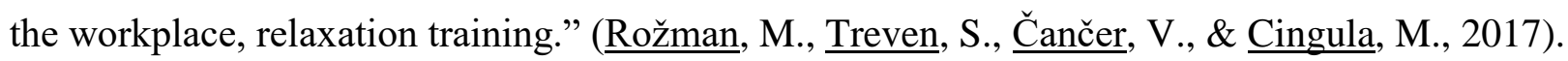




\section{Conclusion}

Future research regarding burnout would be beneficial towards the continued understanding of global workplace behavior as it relates to the topic of situational factors, stress management, and worklife balance that can promote mental health and support individuals. As more employees are identifying themselves as "not engaged" or "actively disengaged" when they describe their current work situation, it shows that it is vital for changes within the workplace. By the WHO, advocating awareness regarding the workplace as a severe issue affecting employees, it may be possible that more people will receive the assistance that they need for work-life balance. A healthy work environment is beneficial for employees to avoid sickness and physical deterioration, secure functional cognitive behavior, and promote positive and active attitude towards a balanced life. It is suggested that companies will need to find different resources that can introduce and implement burnout assistance to employees to allow communication, motivation, support services, and positive moral leadership. All of these things are a vital part of an employee and employer workplace balance. 


\section{References}

Bass, B. M. (1997). Does the transactional-transformational leadership paradigm transcend organizational and national boundaries? American Psychologist.

Becker, F. D., \& Steele, F. (1995). The Jossey-Bass management series. Workplace by design: Mapping the high-performance workscape. San Francisco, CA, US: Jossey-Bass.

Del Bosque, D., \& Skarl, S. (2016). Keeping workplace burnout at bay: Online coping and prevention resources. College \& Research Libraries News, 77(7), 349-355. Retrieved from: https://crln.acrl.org/index.php/crlnews/article/view/9525/10838

Gilbert, P. (2000). The relationship of shame, social anxiety and depression: The role of the evaluation of social rank. Clinical Psychology \& Psychotherapy: An International Journal of Theory \& Practice, 7(3), 174-189.

Golonka, K., Mojsa-Kaja, J., Gawlowska, M., \& Popiel, K. (2017). Cognitive Impairments in Occupational Burnout - Error Processing and Its Indices of Reactive and Proactive Control. Frontiers in psychology, 8, 676. https://doi.org/10.3389/fpsyg.2017.00676

Jimenez, P., \& Dunkl, A. (2017). The buffering effect of workplace resources on the relationship between the areas of worklife and burnout. Frontiers in psychology, 8, 12. Retrieved from: https://www.frontiersin.org/articles/10.3389/fpsyg.2017.00012/full

Jou, R.-C., Kuo, C.-W., \& Tang, M.-L. (2013). A study of job stress and turnover tendency among air traffic controllers: The mediating effects of job satisfaction. Transportation Research Part E: Logistics and Transportation Review,57, 95-104.

Kyriacou, C. (1987). Teacher stress and burnout: An international review. Educational Research,29(2), 146-152.

Nogueira, L.S., Sousa, R.M.C., Guedes, E.S., Santos, M.A.D., Turrini, RNT., Cruz, D.A.L.M.D., (2018). Burnout and Nursing Work Environment in Public Health Institutions. Revista Brasileira de Enfermagem,71(2), 336-342. Retrieved from: https://dx.doi.org/10.1590/00347167-2016-0524

Peterson, C., Maier, S. F., \& Seligman, M. E. P. (1993). Learned helplessness: A theory for the age of personal control. New York: Oxford University Press.

Rožman, M., Grinkevich, A., Tominc, P. (2019). Occupational Stress, Symptoms of Burnout in 
the Workplace and Work Satisfaction of the Age-diverse Employees. Organizacija, 52(1), 4652. Retrieved from:10.2478/orga-2019-0005

Schonfeld, I. S., \& Bianchi, R. (2016). Burnout and depression: two entities or one?. Journal of clinical psychology, 72(1), 22-37. Retrieved from: https://academicworks.cuny.edu/cgi/viewcontent.cgi?article=1276\&context=gc_pubs

Slick, S. K. (1997). Assessing versus assisting: The supervisor's roles in the complex dynamics of the student teaching triad. Teaching and Teacher Education,13(7), 713-726.

Van Dam, A., Keijsers, G. P. J., Eling, P. A. T. M., \& Becker, E. S. (2015). Burnout and impaired cognitive performance; Review of evidence, underlying processes and future directions. In T. N. Winston (Ed), Handbook on burnout and sleep deprivation: Risk factors, management strategies and impact on performance and behaviour (pp. 113-128). New York: Nova.

World Health Organization. (2019, May). Mental Health in the Workplace. Retrieved from https://www.who.int/mental_health/in_the_workplace/en/

World Health Organization. (2019, May). Burn-out an Occupational Phenomenon: International Classification of Diseases. Retrieved from https://www.who.int/mental_health/evidence/burnout/en/

Yankelevich, M., Broadfoot, A., Gillespie, J. Z., Gillespie, M. A., \& Guidroz, A. (2012). General job stress: A unidimensional measure and its non-linear relations with outcome variables. Stress and Health,28(2), 137-148.

Yu, X., Wang, P., Zhai, X., Dai, H., \& Yang, Q. (2015). The effect of work stress on job burnout among teachers: The mediating role of self-efficacy. Social Indicators Research, 122(3), 701708. doi:http://dx.doi.org/10.1007/s11205-014-0716-5

Zhu, W., Chew K.H., \& Spangler, W. (2005). CEO transformational leadership and organizational outcomes: The mediating role of human-capital-enhancing human resource management. The Leadership Quarterly, 16(1), pp.39-52. Retrieved from: https://doi.org/10.1016/j.leaqua.2004.06.001 


\section{Appendix I}

The research questions discussed during each interview were:

1. How many hours do you work each week on average?

2. Do you answer phone calls outside of your work hours?

- Is this a requirement for your position at work?

- How do you feel answering calls outside of your work hours?

3. Do you answer work emails outside of your work hours?

- Is this a requirement for your position at work?

- Do your work emails go directly to your cellphone?

- How do you feel replying to emails outside of your work hours?

4. What do you consider to be self-care?

5. How much time do you spend on yourself each week?

- Do you consider the amount of time you spend on yourself weekly enough?

6. Describe what professionalism would be in the workplace?

- Do you think that most people subscribe to your definition of workplace professionalism?

7. Can you describe your relationships with others at your workplace?

- How do these relationships affect you?

8. Do you know what workplace burnout is?

- Would you consider yourself to fall under this category?

9. Do you think your workplace has a direct impact on your health?

10. What can organizations/workplaces do to help relieve workplace burnout? 